\title{
Projects Management in Technology Start-ups for Mobile Software Development
}

\author{
https://doi.org/10.3991/ijim.v15i07.19291 \\ Pavel Petrov ${ }^{\left({ }^{\circ}\right)}$, Svetoslav Ivanov, Petar Dimitrov \\ University of Economics - Varna, Varna, Bulgaria \\ petrov@ue-varna.bg \\ Georgi Dimitrov \\ University of Library Studies and Information Technologies, Sofia, Bulgaria \\ Oleksii Bychkov \\ Taras Shevchenko National University of Kyiv, Kyiv, Ukraine
}

\begin{abstract}
The management of the technology start-up company for development of software for mobile devices includes various activities such as creation of specification, development, implementation, sale, and maintenance of software for mobile devices, as well as services for it. Usually the main activity is the production and maintenance of software for mobile devices, but there may be different options and sub-options in the business model of the technology start-up, which are divided into two main categories - products and services. In recent years, there has been a trend to move into a business with service providers. The objective of our study is to outline some specifics about the operation of technology start-up companies for mobile software development in areas such as the management of human and financial resources, choosing the suitable methodology for software development and business model to follow.
\end{abstract}

Keywords—-start-ups, software methodologies, business models, mobile software development.

\section{Introduction}

Some of the activities of the technology start-up company for development of software for mobile devices include creation of specification, development, implementation, sale, and maintenance of software for mobile devices, as well as services for it. Usually, the main activity is the production and maintenance of software for mobile devices, but there may be different options and sub-options in the business model of the technology start-up, which are divided into two main categories - products and services. In recent years, there has been a trend to move into a business with service providers. In its most general form, the activity can be classified as: 
- Assignment proceedings by clients (external contracting authorities);

- Production and sale of own trade products

- Own components for use in products of other developers

- Individual services for adjustment, adaptation and implementation of a product

- Maintenance of existing and implemented products of the above categories

Each option has its specifics in terms of contracting authority, assignment, financing, result, life cycle, repeatability, etc., while the activity of the technology start-up company can be a mixture of different options with different products. Each of them can be implemented in one or a series of projects. The projects, as it is known, have basic parameters such as: scope, quality, price, and time, which are determined in a development contract with an external client or an assignment for development of own product. Start-ups in the software mobile development face some specific challenges compared to other software development $[6,13,27]$. For example: a large number of competitors create pressure for the product to be launched as early as possible; the requirements are changed constantly in accordance with emerging trends in technology $[14,17,30,31]$; some devices have limited capabilities such as storage, connectivity or battery capacity, etc.

\section{Projects Types and their Specific Parameters}

A product for an external client is in accordance with an assigned project (from direct contact, tender, upgrade of another developed product, others). The parameters are defined in a contract before actual work on the project begins. Sometimes the time available for this can be short. The scope and specification are set by the client or prepared by an analyst in the technology start-up. It is common practice for the scope not to be fully defined in the contract, or even parts of it not to be fully defined or to be described without details. The customer often wants to change or add requirements when they see how the software for mobile devices works, or the given requirements are not adequate. The quality level is set individually for every project $[2,3,8,16]$. It can be part of national or international standard. The time for project implementation may be different, but according to our observations it usually lasts from one week to one year. In terms of scope, cost and time constraints, projects can be divided into $[5,7,20,24]$ :

- Fixed in terms of scope, price and time that the contractor must comply with

- Fixed with the option changes in the requirements to change time and price

- With variable scope, time and price based on time and resources spent

Regardless of the type, company obligation is to complete the project within the agreed scope, quality, time, and budget. Although there are types with variable parameters, depending on both the client and the case, each type has a final (unknown at the beginning) financial, time and psychological limit (relative to the contract). An additional advantage of the company can be if it works not only towards the successful completion of a project, but also for providing additional features that exceed the 
expected results. This is important if the developed product is of paramount importance to the customer or if there is potential for both a good recommendation and a product that will result in a potential upgrade and maintenance orders and a starting point for a new niche market. At this point, the management and the entrepreneur need a shrewd assessment of the associated real opportunities and risks.

Own products are an initiative of the company, which has the responsibility for planning, specification, implementation, and financing. The requirements are from an internal client (product manager, marketing specialists), but are supplemented in a different form with feedback from users. Quality and price (budget) are also determined by the company in accordance with the chosen market positioning and opportunities.

The development of own product offers better opportunities for profit with sales multiplication, but more dynamics in requirements, development process and parameters, and in general - more challenges should be expected. The latter includes the choice of the exact market niche and time of launch, adequacy of future consumer needs, technologies and coverage standards, higher quality standards, a wide range of users, compatibility with different environments, dynamics in technology development, competition with competitors for product launch, technological obsolescence, a strong manufacturer to occupy the niche with its package, a short period for market sales, etc. Unlike an individual product, owning a product requires better documentation, more end-user support, and internal support documentation. Implementation in projects is usually done in an initial larger project for the first version for 6-12 months and shorter for subsequent versions (up to 3-6 months).

The own component is an analogue of the own product. The component is an intermediate product, a finished "part" included in software products. Usually its users are professionals in the industry (developers, programmers, designers, designers). It makes sure that the documentation and maintenance are oriented towards professionals. The benefit for the technology start-up is the ability to sell on a specialized market and the use of market niches of other "producers" of the final product. Details of the components are given below.

Individual services are one-time actions and services for specific clients (usually external). In some cases, when a service is more complex, the activities could be interpreted as working on an external client's project. The difference is that these are services for setting up, implementing, or integrating an existing product - own, from an external project or from a third party.

Product maintenance $[10,26,35]$ is common for contractual terms and obligations. It can be constant with monitoring or support in case of a problem requested by the client. The specific about those activities is that they are focused on monitoring or on dealing with complaints about defects. Those maintenance activities may also include minimal product improvement and refinement.

The maintenance of software for mobile devices, also known as support, is related to ensuring the normal operation of a built and implemented product. It involves making changes to correct detected errors, adapt to a new environment, OS, hardware, to improve existing and add new functionalities. Regular monitoring and documentation, which aim to monitor the functioning of the product, serves to identify irregularities 
and document. Naturally, these activities are subject to policy or contract. The main tasks are:

- Product research, preparation of documentation for maintenance, training

- Regular monitoring of the supported software

- Accepting complaints from customers and communicating with them

- Problem analysis, change design, programming and testing

- Integration and systematic testing of the product

- Description of the changes in operational and accompanying documentation

Maintenance is a labor-intensive activity, which is why many automation tools have been created, such as modular and integration testing, configuration management, documentation, integrated and easily adaptable development environments, and others.

\section{Management of Human and Financial Resources in the Development of Software for Mobile Devices}

Mobile software development is a highly intellectual job of creating a new product. Some authors $[11,12,25]$ even describe it as inventing a new product with a learning process. Unlike standard production, where the product is of the same type, here a completely new product is formed. The dynamics of requirements and technologies bring additional complexity. Complexity management and product innovation can be obtained with the right team of specialists, process, environment, and management. In this sense, the importance of human resource management as an essential factor for success stands out. Some specific features regarding human resource management in a technology start-up are the following $[4,15,22,29]$ :

- A team of professionals who effectively create an innovative and quality product

- Need for new knowledge, skills and qualities of specialists

- High share of human resources expenditures and trend of wage growth and mobility

Specific requirements for management regarding the motivation of human resources and the importance of the first group comes from the desired result - a quality new marketable product. Here we must consider the role of training, which we will define in three groups:

- For professional skills, technologies and innovations for a specific environment

- In adequate approaches, methods, techniques for improving the development process

- Improving work through self-learning (feedback and gaining experience)

The technological development of the developer tools, automation in programming and testing shift the focus of activities and skills. Therefore, we need not just programmers, but creative individuals, ready for autonomy, responsibility, and continu- 
ous training. In order to work successfully in business, you need a certain value system and culture, which must also be taken into account when selecting a team. The main challenge for technology start-ups is to avoid and overcome some negative processes. For example, in the traditional motivational structure, after achieving safety in the workplace, there is a process of establishing good connections and contacts with colleagues and managers and maintaining the status quo for a long period of time. This creates serious obstacles to initiative, risk-taking and innovation.

The importance of the human resources factor is also determined for financial reasons. It has a predominant share in the cost of the final product and a tendency towards increasing cost and mobility of professionals. According to one study, the ratio of labor productivity between "best" and "weakest" is 10:1, and the most significant factor is who you work with as a team [4,32]. The research is from competitions; shows that the best are 2-2.5 times better than the average level, and factors such as programming language (of the same level), experience (over 6 months) and salary are of minimal importance (in percentages). Admitted defects and better working environment led to better time and result.

Greater emphasis is needed on effective management, without which any organizational and methodological change cannot succeed. In the first place is the selection and organizational culture. This is followed by a sense of personal security so that communication in the team and the process can proceed normally with a focus on work [1,21].

What matters is the place of team motivation, which is a broad-spectrum process with many factors (not just monetary incentives). There are many theories and models for motivation, and their proper application increases productivity and organizational performance $[18,19,33,34]$. Effective leadership is also important for the company's success. It is about guiding the team and making decisions. The team leader must integrate knowledge and understanding of business needs, technologies, and their use. It is wrong for him to be busy with administrative task management and separated from the team $[9,23,28]$. Human resources are the factor with the greatest complexity of management, but the only one that can contribute to the significant success of the technology start-up.

The issue of effective management of financial resources is before every company. The technology start-up has a special weight, as it usually has less capital and cannot rely on it as a significant competitive advantage. Moreover, when developing and promoting new products, the company can rarely rely on long-term solid financing. Therefore, good financial and development management is imperative, and it is inextricably linked to good human resource management.

\section{Conclusion}

In our study we outlined some specifics about the management of start-ups developing mobile software. The findings are fully applicable to technological software innovations in mobile technologies. The differences compared to other companies is in the set of tools used for the implementation. Moreover, it is possible that the vari- 
ous business model for mobile software development and supporting services to run in parallel, exchanging between them product requirements, developed intermediate product, product tests and correction based on customers' requirements.

\section{Acknowledgement}

This research is supported by NPD-254/2019 and NPD-255/2019 from the University of Economics - Varna, Science Fund.

\section{$6 \quad$ References}

[1] Aldahmash, A., Gravell, A. M., \& Howard, Y. (2017). A review on the critical success factors of agile software development. In European conference on software process improvement, Springer. pp.504-512. https://doi.org/10.1007/978-3-319-64218-5_41

[2] Balabanova, I., Georgiev, G., et al. (2016). Classification of Teletraffic Service Devices by K-NN, ANFIS and ANN Classificators. In IEEE International Black Sea Conference on Communications and Networking (BlackSeaCom), pp.1-5. https://doi.org/10.1109/Black SeaCom.2016.7901585

[3] Bulut F., \& Erol M.H. (2018). A Real-Time Dynamic Route Control Approach on Google Maps using Integer Programming Methods. International Journal of Next-Generation Computing, 9(3), pp.189-202.

[4] Cockburn, A. (2002). Agile Software Development. Addison-Wesley.

[5] Cockburn, A. (2005). Crystal Clear: A Human-Powered Methodology for Small Teams. Addison-Wesley.

[6] Dimitrov, G., Panayotova, G., Garvanov, I., et al. (2016). Performance analysis of the method for social search of information in university information systems. In 3rd International Conference on Artificial Intelligence and Pattern Recognition (AIPR), Lodz, Poland, IEEE, pp.149-153. https://doi.org/10.1109/ICAIPR.2016.7585228

[7] El Omari, M., Erramdani, M., \& Rhouati, A. (2020). A Model Driven Approach for Generating Angular 7 Applications. International Journal of Recent Contributions from Engineering, Science \& IT (iJES), 8(2). pp.36-45. https://doi.org/10.3991/ijes.v8i2.14131

[8] Georgiev G., Balabanova I., et al. (2018). Identification of Sine, Squire, Triangle and Sawtooth Waveforms with Uniform White and Inverse F Noises by Adaptive Neuro - Fuzzy Interface System. Journal of Engineering Science and Technology Review. 11(3), pp.128132. https://doi.org/10.25103/jestr.113.17

[9] Jacob, N. M. (2019). A Review of Mobile Application Development in the Agile Software Development Environment. Global Journal of Computer Science and Technology, 19(1). pp.19-22.

[10] Kuyumdzhiev, I. (2019). Comparing Backup and Restore Eficiency in MySQL, MS SQL Server and MongoDB. In 19 International Multidisciplinary Scientific Geoconference SGEM 2019, 19(2.1), pp.167-174. https://doi.org/10.5593/sgem2019/2.1/S07.022

[11] Larman, C., \& Vodde, B. (2016). Large-scale scrum: More with LeSS. Addison-Wesley Professional.

[12] Malkawi, R., Alzaqebah, M., et al. (2019). The impact of the digital storytelling rubrics on the social media engagements. International Journal of Computer Applications in Technology, 59(3), pp.269-275. https://doi.org/10.1504/IJCAT.2019.098605 https://doi. org/10.1504/ijcat.2019.10020111 
[13] Malkawi, R., Saifan, A. A., et al. (2020) Data Mining Tools Evaluation Based on their Quality Attributes. International Journal of Advanced Science and Technology, 29(3). pp.13867-13890.

[14] Marinova, R. \& Momcheva, G. (2019). Survey of Information Technology Undergraduate Degree Programs in Canada, In 2019 IEEE Canadian Conference of Electrical and Computer Engineering (CCECE), pp.1-4. https://doi.org/10.1109/CCECE.2019.8861715

[15] McConnell, S. (2004). Code complete. Pearson Education.

[16] Ovacıklı A.K., Pääjärvi P., LeBlanc J.P., \& Carlson J.E. (2015). Recovering periodic impulsive signals through skewness maximization. IEEE Transactions on Signal Processing. 64(6), pp.1586-1596. https://doi.org/10.1109/TSP.2015.2502549

[17] Panayotova, G., Dimitrov, G., et al. (2016). Modeling and data processing of information systems. In 3rd International Conference on Artificial Intelligence and Pattern Recognition (AIPR), Lodz, Poland, IEEE, pp.154-158. https://doi.org/10.1109/ICAIPR.2016.7585 $\underline{229}$

[18] Pashev G., Rusenova L., Totkov G., \& Gaftandzhieva S. (2020). Adaptive Workplace ELearning Model. TEM Journal, 9(2), pp.613-618. https://doi.org/10.18421/TEM92-25

[19] Pashev, G., Rusenova, L., Totkov, G., \& Gaftandzhieva, S. (2019). Business Process Modelling \& Execution Application in Work Education Domain. TEM Journal, 8(3), pp.992997. https://doi.org/10.18421/TEM83-42

[20] Petrov, P., \& Valov, N. (2019). Digitalization of Banking Services and Methodology for Building and Functioning of Fintech Companies. Izvestia Journal of the Union of Scientists - Varna. Economic Sciences Series, 8(1). pp.110-117. https://doi.org/10.36997/I JUSV-ESS/2019.8.1.110

[21] Petrov, P., Dimitrov, P., et al. (2020). Using the Universal Two Factor Authentication Method in Web Applications by Software Emulated Device. In 20 International Multidisciplinary Scientific Geoconference SGEM 2020: Conference Proceedings, 20(2.1). https://doi.org/10.5593/sgem2020/2.1/s07.052

[22] Petrova, S., Sergeev, A., et al. (2019). Online Public Access Catalogs in Bulgarian University Libraries an Empirical Study of Seven-Year Evolution. In 12th Annual International Conference of Education, Research and Innovation (ICERI), pp.230-236. https://doi.org/10.21125/iceri.2019.0091

[23] Petrova, S., Stefanov, S., et al. (2019). Information systems used in Bulgarian university libraries as online public access catalogs. In International Multidisciplinary Scientific GeoConference Surveying Geology and Mining Ecology Management (SGEM), 19(2.1), pp.353-360. https://doi.org/10.5593/sgem2019/2.1/S07.046

[24] Poppendieck, M., \& Poppendieck, T. (2013). The Lean Mindset. Addison-Wesley Professional.

[25] Prahani, B., Jatmiko, B., et al. (2020). Blended Web Mobile Learning (BWML) model to improve students' higher order thinking skills. International Journal of Emerging Technologies in Learning (iJET), 15(11). pp.42-55. https://doi.org/10.3991/ijet.v15i11.128 53

[26] Radev, M. (2017). Using the TOPSIS Method to Evaluate Projects for Virtualization. Izvestia Journal of the Union of Scientists - Varna. Economic Sciences Series. 6(2), pp.234-241.

[27] Radev, M., \& Aleksandrova, Y. (2013). Combining Virtualization Technologies in SOAApplication. In 3rd International Conference on Application of Information and Communication Technology and Statistics in Economy and Education (ICAICTSEE-2013): Conference Proceedings. pp.56-61.

[28] Salvetti, F., Bertagni, B. (2020). Leadership 5.0: An Agile Mindset for a Digital Future. International Journal of Advanced Corporate Learning (iJAC), 13(2), pp.57-66. https:// doi.org/10.3991/ijac.v13i2.17033 
[29] Schreiber, R. R., \& Zylka, M. P. (2020). Social Network Analysis in Software Development Projects: A Systematic Literature Review. International Journal of Software Engineering and Knowledge Engineering, 30(03). pp.321-362. https://doi.org/10.11 42/S021819402050014X

[30] Stoev, S. (2016). Product Risk Management in Information Systems Implementation. Izvestia Journal of the Union of Scientists - Varna. Economic Sciences Series. 5(2), pp.109-116.

[31] Stoev, S. (2017). Integration of Risk Management Processes into the Business of IT Companies. Izvestia Journal of the Union of Scientists - Varna. Economic Sciences Series. 6(2), pp.225-233.

[32] Stoev, S. (2019) Using of additional packages of components for accelerated application development. Izvestia Journal of the Union of Scientists - Varna, Union of Scientists Varna, 8(2). pp.171-179. https://doi.org/10.36997/IJUSV-ESS/2019.8.2.171

[33] Suciu, G., Boscher, C., Prioux, L., Pasat, A., \& Dobre, C. (2017). Insights into Collaborative Platforms for Social Media Use Cases. Studies in Informatics and Control, 26(4), pp.435-440. https://doi.org/10.24846/v26i4y201707

[34] Vasilescu, C., Suciu, G., \& Pasat, A. (2019). A New Method to Help the Human Resources Staff to Find the Right Candidates, Based on Deep Learning. In The International Scientific Conference eLearning and Software for Education, "Carol I" National Defence University, v.3, pp.240-246. https://doi.org/10.12753/2066-026X-19-170

[35] Vasilev, J., \& Stoyanova, M. (2019). Information Sharing with Upstream Partners of Supply Chains. In 19 International Multidisciplinary Scientific Geoconference SGEM 2019, 19(2.1), pp.329-336. https://doi.org/10.5593/sgem2019/2.1/S07.043

\section{$7 \quad$ Authors}

Dr. Pavel Petrov is working as Associate Professor in the Department of Informatics and Computer Science at the University of Economics - Varna, Varna, Bulgaria. His research interests include distributed web systems, cloud computing and programmable matter. E-mail: petrov@ue-varna.bg

Svetoslav Ivanov is $\mathrm{PhD}$ candidate in the field of application of computer technology in economics at the University of Economics - Varna, Varna, Bulgaria. $\mathrm{He}$ is currently working as a Senior Software Engineer in a private company. E-mail: svetoslav_ivanov@ue-varna.bg

Petar Dimitrov is $\mathrm{PhD}$ candidate in the field of Computer Science at the University of Economics - Varna, Varna, Bulgaria. He is currently working as a Head of Software Department in the Research and Application of New Information and Communication Technologies Center (RANICTC) at UE-Varna. E-mail: p.d.dimitrov@ue-varna.bg

Dr. Georgi Dimitrov is working as Professor in the University of Library Studies and Information Technologies, Sofia, Bulgaria. He is Vice Dean of Department of Information Technology. E-mail: g.dimitrov@unibit.bg

Dr. Oleksii Bychkov is working as Associate Professor in the Taras Shevchenko National University of Kyiv, Kyiv, Ukraine. He is Head of the Department of Program Systems and Technology. E-mail: bos.knu@gmail.com

Article submitted 2020-10-18. Resubmitted 2020-11-09. Final acceptance 2020-11-09. Final version published as submitted by the authors. 